\title{
Antioxidant vitamin supplements do not reduce reactive oxygen species activity in Helicobacter pylori gastritis in the short term
}

\author{
Simon M. Everett*, Ian M. Drake ${ }^{2}$, Kay L. M. White ${ }^{1}$, Nic P. Mapstone ${ }^{1}$, Douglas M. Chalmers ${ }^{1}$, Chris \\ J. Schorah ${ }^{1}$ and Anthony T. R. Axon ${ }^{1}$ \\ ${ }^{1}$ The Centre for Digestive Diseases, The General Infirmary at Leeds, Great George Street, Leeds LS1 3EX, UK \\ ${ }^{2}$ Chorley and South Ribble District General Hospital, Preston Road, Chorley, Lancashire, PR7 IPP, UK
}

(Received 20 February 2001 - Revised 17 July 2001 - Accepted 28 August 2001)

\begin{abstract}
Reactive oxygen species have been implicated in Helicobacter pylori-mediated gastric carcinogenesis, whereas diets high in antioxidant vitamins $\mathrm{C}$ and $\mathrm{E}$ are protective. We have examined the effect of vitamin $\mathrm{C}$ and $\mathrm{E}$ supplements in combination with $H$. pylori eradication on reactive oxygen species activity in $H$. pylori gastritis. $H$. pylori-positive patients were randomized into four groups: triple therapy alone (Bismuth chelate, tetracycline, and metronidazole for 2 weeks), vitamins alone ( $200 \mathrm{mg}$ vitamin $\mathrm{C}$ and $50 \mathrm{mg}$ vitamin $\mathrm{E}$, both twice per day for 4 weeks), both treatments or neither. Plasma and mucosal ascorbic acid, malondialdehyde and reactive oxygen species were determined before and after treatment. Compared with normal controls ( $n$ 61), H. pylori-positive patients $(n 117)$ had higher mucosal reactive oxygen species and malondialdehyde levels and lower plasma ascorbic acid. Plasma ascorbic acid doubled in both groups of patients receiving vitamins and mucosal levels also increased. Malondialdehyde and reactive oxygen species fell in patients in whom H. pylori was eradicated but vitamin supplements were not effective either alone or in combination with $H$. pylori eradication. Supplements of vitamins C and E do not significantly reduce mucosal reactive oxygen species damage in $H$. pylori gastritis.
\end{abstract}

Ascorbic acid: Vitamin C: Vitamin E: Reactive oxygen species: Malondialdehyde: Gastric carcinoma: Helicobacter pylori

Gastric cancer is the second commonest cause of death from malignant disease worldwide (Parkin et al. 1993). Strategies to prevent this condition are therefore of great importance. It is well established that diets containing a high intake of the antioxidant vitamin $\mathrm{C}$ are associated with reduced risk of developing gastric cancer (Block, 1991). Vitamin E, which also has antioxidant properties, may play an additional protective role (Knekt et al. 1991). In recent years it has also been recognized that chronic infection of the gastric mucosa by Helicobacter pylori plays a pivotal role in gastric carcinogenesis (International Agency for Research on Cancer, 1994).

Infection of the gastric mucosa with Helicobacter pylori usually causes both an acute and chronic inflammatory cell infiltrate, leading to an increase in reactive oxygen species (ROS) (Davies et al. 1994). These are highly reactive compounds capable of combining with DNA in a number of potentially genotoxic ways (Jackson et al. 1989; Guyton \& Kensler, 1993). ROS can react with the lipid bilayer releasing peroxidation products, such as malondialdehyde. These compounds, which are also able to react with DNA, have been shown to accumulate in $H$. pylori gastritis (Marnett, 1994; Farinati et al. 1996; Drake et al. 1998). These processes could lead to alterations in the structure of DNA facilitating mutations and carcinogenesis.

In the normal stomach, ascorbic acid and total vitamin $\mathrm{C}$ are highly concentrated from plasma into the mucosa and (to a lesser extent) gastric juice (Sobala et al. 1989; Banerjee et al. 1994). Vitamin C exists as ascorbic acid or dehydroascorbic acid. Ascorbic acid is the reduced form of the vitamin and can act as a potent antioxidant, able to scavenge ROS in gastric mucosa (Frei, 1991; Drake et al. 1996). This has been proposed as one means by which it exerts an anticarcinogenic effect (Correa, 1995). Ascorbic acid may also prevent formation of $N$-nitroso compounds in gastric juice by scavenging nitrite (Mirvish et al. 1972). Ascorbic acid is found principally in the aqueous phase

\footnotetext{
Abbreviation: ROS, reactive oxygen species.

* Corresponding author: Dr Simon M. Everest, fax +44 113242 9722, email severett@doctors.net.uk
} 
whereas vitamin $E$ ( $\alpha$-tocopherol) exists mainly in the lipid phase. Vitamin E regenerates ascorbic acid from its oxidised form dehydroascorbic acid and acts synergistically with ascorbic acid to prevent lipid peroxidation (Cadenas et al. 1996).

One way in which it may be possible to prevent carcinogenesis would be to reduce ROS damage to cellular constituents, especially DNA. It has been demonstrated that eradication of $H$. pylori leads to a reduction in ROS activity in the gastric mucosa (Drake et al. 1998). An alternative or additional approach might be to supplement antioxidant vitamins in the diet. The aim of the present study was, therefore, to determine whether dietary supplements of vitamins $\mathrm{C}$ and $\mathrm{E}$ are able to reduce levels of ROS and lipid peroxidation in the gastric mucosa, either alone or in combination with $H$. pylori eradication. We have randomized $H$. pylori positive patients in a $2 \times 2$ study design to receive eradication therapy or placebo for 2 weeks followed by vitamins $\mathrm{C}$ and $\mathrm{E}$ or placebo for 4 weeks (making four separate randomized groups) and assessed ROS and lipid peroxidation before and at the end of treatment.

\section{Methods \\ Study design}

This was a randomized, double blind, controlled trial. Patients with dyspepsia aged between 18 and 80 years attending for routine out-patient endoscopy were invited to participate. Patients were excluded if any of the following were present: pregnancy or lactation, significant comorbidity, antibiotic use in the previous 6 weeks, previous attempts at $H$. pylori eradication, previous gastric surgery or a previous history of alcohol or drug abuse.

All patients attended for endoscopy at the same time (14.00 hours) after an overnight fast. Prior to endoscopy, a $10 \mathrm{ml}$ sample of venous blood was withdrawn into a lithium heparin tube. Antral biopsies were taken for $H$. pylori culture and urease test, along with two biopsies from antrum and corpus for histological assessment. If at least two out of these three tests were positive then patients were deemed $H$. pylori positive, and $H$. pylori negative if all three were negative. Control patients were also attending for investigation of dyspepsia but had all tests negative for $H$. pylori and histologically normal gastric mucosa. Further biopsies were taken from all patients as follows: two from the antrum for luminol-enhanced chemiluminescence, one from the antrum for malondialdehyde assessment, and one from both antrum and corpus for ascorbic acid and vitamin $\mathrm{C}$ determination.

H. pylori-positive patients were randomized on a $1: 1: 1: 1$ basis to receive one of the following treatments: (1) colloidal bismuth subcitrate $(120 \mathrm{mg})$ plus tetracycline (500 mg), both four times per day, plus metronidazole (400 mg) three times per day (triple therapy), followed by ascorbic acid (200 mg) plus vitamin E, $\alpha$-tocopherol $(50 \mathrm{mg})$, both twice per day; (2) triple therapy followed by vitamin placebo; (3) triple therapy placebo followed by vitamins $\mathrm{C}$ and $\mathrm{E}$; or (4) triple therapy placebo followed by vitamin placebo. In all cases, antibiotic (triple) therapy or its placebo was for 2 weeks followed by vitamin supplementation or its placebo for 4 weeks. Thus, patients received triple therapy and antioxidant vitamins (triplevitamins), triple therapy alone (triple-placebo), vitamins alone (placebo-vitamins), or neither (placebo-placebo). Consecutive patients were allocated treatment randomly according to a list kept in pharmacy. Placebo tablets (lactose) were identical in appearance to the study drugs and all drugs were dispensed by the pharmacy to maintain investigator blinding. At the end of the 6-week treatment period, patients returned for repeat endoscopy and sampling. Patients were instructed not to take tablets on the day of endoscopy. The study was approved by the Local Research Ethics Committee and all patients gave written informed consent.

\section{Histology}

Biopsies were fixed in $10 \%$ buffered formalin. Sequential $3 \mu \mathrm{m}$ thick sections were cut and stained with haematoxylin and eosin and modified Giemsa's stain. Gastritis was scored from 0-3 for acute inflammation, chronic inflammation, atrophy, intestinal metaplasia and $H$. pylori infection density according to the updated Sydney classification by a single blinded histopathologist (Dixon et al. 1996).

\section{Helicobacter pylori culture}

A single biopsy was immediately transferred to brain-heart infusion broth and incubated microaerophilically at $37^{\circ} \mathrm{C}$ on a VPAT plate (vancomycin, polymyxine B, amphotericin, trimethoprim) for $8 \mathrm{~d}$. Plates were inspected for $H$. pylori at 4, 6 and $8 \mathrm{~d}$.

\section{Luminol-enhanced chemiluminescence}

Chemiluminescence probes such as luminol and lucigenin react with ROS to form 3-aminophthalate and $N$-methylacridone. The excited electrons in these compounds relax with the emission of energy as light which can be detected by a scintillation counter. Luminol has been found to be a more sensitive chemiluminescent probe than lucigenin in colonic and gastric biopsies (Simmonds et al. 1992; Davies et al. 1994). The reaction of $\mathrm{H}_{2} \mathrm{O}_{2}$ and hypochlorite with luminol is catalysed by neutrophil-derived myeloperoxidase; inhibition of this enzyme by sodium azide leads to maximal reduction in chemiluminescence suggesting that these are the most important metabolites detected by this technique. Consistent with this, chemiluminescence results correlate with acute inflammatory scores in mucosal biopsies. Chemiluminescence is also inhibited by catalase and dimethyl superoxide suggesting detection of $\mathrm{H}_{2} \mathrm{O}_{2}$ and hydroxyl radicals respectively. Thus, luminol was selected for the present study as it is a suitable probe to detect neutrophil-derived ROS in gastric biopsies (Drake et al. 1998).

Two antral biopsies from each patient were transferred immediately into pre-oxygenated PBS ( $\mathrm{pH} 7 \cdot 4)$ with added glucose ( $5 \mathrm{~mm}), \mathrm{M}$ and $\mathrm{C}$, and assayed within $3 \mathrm{~h}$. Prior to weighing, each biopsy was added to a pre-counted scintillation vial containing $1 \mathrm{ml} 75 \mu \mathrm{M}$ luminol solution and counted for $5 \mathrm{~min}$ in a liquid scintillation counter set in 
the 'out of coincidence' mode. Three measurements of each sample were made and the mean calculated. The withinsubject CV of this assay, based on ninety-nine pairs of biopsies, was $71 \%$. Although high, this is consistent with previous reports of the variability of this technique, and is small in comparison with a 20 -fold increase in chemiluminescence between inflamed and normal gastric mucosa shown by our results (Simmonds et al. 1992; Davies et al. 1994).

\section{Malondialdehyde}

For each patient, one antral biopsy was snap-frozen in liquid $\mathrm{N}_{2}$ at the time of endoscopy, stored at $-70^{\circ} \mathrm{C}$, and assayed within 2 weeks by a modification of the procedure of Yagi (1976). Following thawing, blotting and weighing, each biopsy was immersed in $4 \mathrm{ml}$ water. Thiobarbituric acid solution $(1 \mathrm{ml})$, made by dissolving $0 \cdot 167 \mathrm{~g}$ thiobarbituric acid solution in $50 \mathrm{ml}$ water - glacial acetic acid $(1: 1, \mathrm{v} / \mathrm{v})$, was then added. A set of malondialdehyde standards was also freshly prepared and added to $1 \mathrm{ml}$ thiobarbituric acid solution prepared in the same way. All mixtures were heated at $100^{\circ} \mathrm{C}$ for $60 \mathrm{~min}$. After cooling on ice, $5 \mathrm{ml}$ butan-1-ol was added to extract the malondialdehyde equivalents. The tubes were centrifuged at $1100 \mathrm{~g}$ for $10 \mathrm{~min}$ to separate the aqueous and butan-1-ol phases. Fluorescence of the butan1-ol phase at $555 \mathrm{~nm}$ was determined using an excitation wavelength of $515 \mathrm{~nm}$. Values from the tissue specimens were compared with the standard solutions. The withinsubject $\mathrm{CV}$ of this technique is $16.8 \%$ (based on paired biopsies from 208 patients).

It should be noted that there can be difficulties in the interpretation of the results of this assay. First, aldehydes other than malondialdehyde produced in lipid peroxidation can be detected. Second, much of the malondialdehyde measured is generated by decomposition of lipid hydroperoxides during the acid-heating stage of the assay. In addition, other compounds such as bilirubin, sugars and amino acids can also be reactive towards thiobarbituric acid. Finally, malondialdehyde detected in this assay may also be generated as a byproduct of cyclooxygenase activity in platelets (Emma et al. 2000). However, the first two of these processes reflect other pathways in lipid peroxidation and suggest that, whilst measuring thiobarbituric acid reactive substances in this assay is not specific for malondialdehyde levels in vivo, it is reflective of lipid peroxidation. This is supported by previous studies that have shown significant correlations between malondialdehyde concentrations measured by this assay and both chemiluminescence and its own DNA adduct, malondialdehyde deoxyguanosine (Drake et al. 1998; Everett et al. 2001). Thus, although nonspecific, results from this assay complement the chemiluminescence results and together these assays provide estimations of neutrophil-derived ROS and consequent lipid peroxidation.

\section{Ascorbic acid and total vitamin C measurements}

Venous blood samples were centrifuged. One $0.5 \mathrm{ml}$ aliquot of plasma was added to $1.0 \mathrm{ml}$ metaphosphoric acid $(20 \mathrm{ml} / \mathrm{l})$. A second $0.5 \mathrm{ml}$ aliquot was added to $9 \mathrm{mg}$ dithiothreitol prior to addition of $1.0 \mathrm{ml}$ of metaphosphoric acid $(20 \mathrm{ml} / \mathrm{l})$ for reduction of dehydroascorbic acid to ascorbic acid and subsequent analysis of total vitamin C. All samples were snap-frozen in liquid $\mathrm{N}_{2}$ and stored at $-70^{\circ} \mathrm{C}$. Prior to analysis, samples were thawed and centrifuged at $1000 \mathrm{~g}$. The supernatant fraction was analysed by HPLC using reversed-phase ion pair chromatography on a $\mathrm{C}_{18}$ column (Sobala et al. 1991). Ascorbic acid was selectively measured using an electrochemical detector set at $350 \mathrm{mV}$. Total vitamin $\mathrm{C}$ (the sum of ascorbic acid and dehydroascorbic acid) was determined from the solutions initially prepared with dithiothreitol after incubation at $45^{\circ} \mathrm{C}$ for $120 \mathrm{~min}$.

Biopsy samples were frozen in liquid $\mathrm{N}_{2}$ immediately after endoscopy, stored at $-70^{\circ} \mathrm{C}$ and assayed within 2 weeks. After thawing, biopsies were homogenized in 0.5$1.0 \mathrm{ml}$ metaphosphoric acid and divided into two parts. For total vitamin $\mathrm{C}$ determination, dithiothreitol was added to one part to a final concentration of $6 \mathrm{mg} / \mathrm{ml}$ and incubated at $45^{\circ} \mathrm{C}$ for $120 \mathrm{~min}$ prior to analysis. HPLC was then performed for both parts as described for plasma. The within-subject $\mathrm{CV}$ for both ascorbic acid and total vitamin $\mathrm{C}$ was $5 \%$.

\section{Statistical analysis}

Data for most variables are skewed, and in some instances normality could not be achieved by log transformation. For consistency, therefore, data are presented as median values with interquartile ranges and non-parametric statistics are used (with the exception of linear regression). For patients receiving triple therapy, results presented are for those in whom $H$. pylori was successfully eradicated, and for patients receiving placebo triple therapy, results presented are for those who remained H. pylori positive at follow-up. The Wilcoxon signed-ranks test was used to compare paired pre- and post-treatment data for the randomized groups. Mann-Whitney $\mathrm{U}$ tests were used for comparison of unpaired data and Kruskall-Wallis test was used for comparison of more than one group. Spearman's $\rho$ was calculated for correlations. To calculate the effect of multiple variables on plasma ascorbic acid, multiple linear regression was used with log conversion of the plasma ascorbic acid to maintain normality and constant variance; data are presented as regression slope (B) with $95 \%$ CI. Two-tailed $P$ values were calculated in all cases; a value $<0.05$ is taken to imply statistical significance. Calculations were performed using SPSS for Windows 8.0 (SPSS UK Ltd, Woking, Surrey).

\section{Results \\ Patients}

H. pylori-positive patients ( $n$ 117) were randomized to treatment. Of these, ninety-eight patients returned for the second visit. Control patients with normal gastric histology and negative $H$. pylori tests ( $n$ 63) were also studied. Sex, age, smoking, alcohol intake, use of non-steroidal antiinflammatory drugs and acid suppressive therapy were recorded prior to the first endoscopy. Patients with normal 


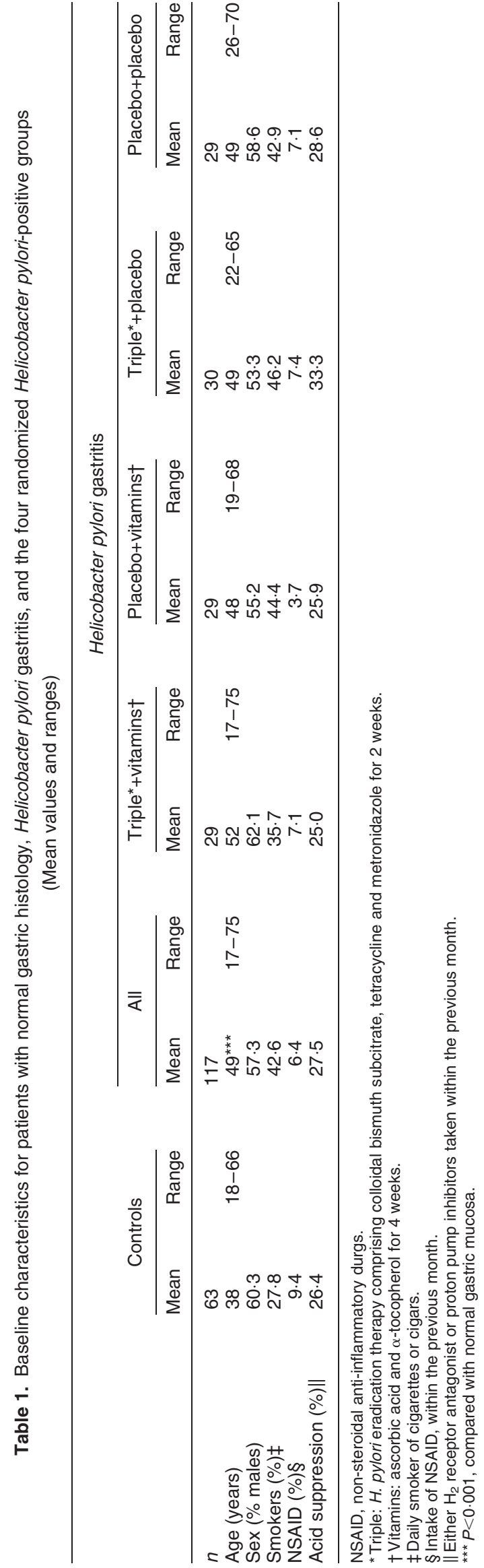

gastric histology were younger than $H$. pylori-positive patients $(P<0 \cdot 001)$, but there were no other significant differences between $H$. pylori-negative and $H$. pylori-positive patients or within the four randomized groups (Table 1).

\section{Baseline results}

There were no significant differences in baseline measurements of malondialdehyde, chemiluminescence and plasma, antral and corpus ascorbic acid and total vitamin $\mathrm{C}$ in the four randomized groups (Table 2).

Antral chemiluminescence and malondialdehyde were both higher in $H$. pylori-positive patients than uninfected patients $(P<0.001$ for both), reflecting increased ROS activity. Malondialdehyde levels correlated significantly with chemiluminescence ( $\rho 0 \cdot 2, P=0 \cdot 009)$.

Plasma ascorbic acid was significantly lower in $H$. pylori-positive patients than in $H$. pylori-negative patients $(P=0.02)$ and the percentage plasma vitamin $\mathrm{C}$ in the reduced ascorbic acid form was also significantly lower in H. pylori-positive than $H$. pylori-negative patients $(89.9 v$. $95.3 \%, P=0.006)$. There were no differences in antral and corpus ascorbic acid levels between $H$. pylori-negative and -positive patients. However, ascorbic acid and total vitamin $\mathrm{C}$ were both significantly higher in the antrum than the corpus. This was true both for $H$. pylori-positive (584.8 v. $356.0 \mu \mathrm{mol} / \mathrm{kg}, P<0.001$ for ascorbic acid and $681.9 v$. $444.6 \mu \mathrm{mol} / \mathrm{kg}, P<0.001$ for total vitamin C) and $H$. pylori-negative patients $(451.4$ v. $340 \cdot 1 \mu \mathrm{mol} / \mathrm{kg}, P<0 \cdot 001$ for ascorbic acid and $572.9 v .392 .9 \mu \mathrm{mol} / \mathrm{kg}, P<0.001$ for vitamin $\mathrm{C}$ ). There was a significant positive correlation between chemiluminescence and antral ascorbic acid ( $\rho 0.19, P=0.02)$ and total vitamin $\mathrm{C}(\rho 0 \cdot 17, P=0.03)$. No such correlation existed between malondialdehyde and either ascorbic acid or total vitamin $\mathrm{C}$.

Chemiluminescence and malondialdehyde were not affected by patient sex, smoking history (smokers $v$. nonsmokers), intake of non-steroidal anti-inflammatory drugs or use of acid-suppressive therapy. Chemiluminescence correlated significantly with age $(\rho 0 \cdot 27, P<0 \cdot 001)$. This correlation was not evident, however, when analysis was limited to $H$. pylori-positive patients $(\rho 0.02, P=0.8)$, suggesting that this is a result of confounding by the older age of $H$. pylori-positive patients.

Plasma ascorbic acid $(16.5 v .47 \cdot 1 \mu \mathrm{mol} / 1, P=0 \cdot 02)$, total plasma vitamin $\mathrm{C}(18 \cdot 2$ v. $50 \cdot 5 \mu \mathrm{mol} / \mathrm{l}, P<0 \cdot 001)$, antral ascorbic acid $(403.7 v .633 .1 \mu \mathrm{mol} / \mathrm{kg}, P=0.007)$ and total antral vitamin $\mathrm{C}(538.3$ v. $687.0 \mu \mathrm{mol} / \mathrm{kg}, P=0 \cdot 01)$ were all lower in smokers than non-smokers, and plasma ascorbic acid (30.7 v. $44.9 \mu \mathrm{mol} / 1, P=0.03)$ and total plasma vitamin C (35.8 v. $47.7 \mu \mathrm{mol} / 1, P=0.05)$ were both lower in males than females. Furthermore, plasma ascorbic acid and total plasma vitamin $\mathrm{C}$ correlated negatively with age $(\rho-0 \cdot 21$, $P=0.008$ and $\rho-0.21, P=0.007$ respectively). There were no other significant correlations between age and measures of ascorbic acid or total vitamin $\mathrm{C}$. In order to determine which of age, sex, smoking and $H$. pylori infection were most important in determining plasma ascorbic acid concentrations a multiple linear regression model was constructed, with log-converted plasma ascorbic acid as the dependent factor. Age $(\mathrm{B}=-0.07,95 \%$ CI -0.01 , 
$-0 \cdot 003, P=0 \cdot 002)$, female sex $(\mathrm{B}=0 \cdot 17,95 \%$ CI $0 \cdot 06$, $0 \cdot 29, P=0 \cdot 004)$ and smoking $(\mathrm{B}=-0 \cdot 10,95 \% \mathrm{CI}-0 \cdot 15$, $-0 \cdot 05, P<0 \cdot 001)$ all remained significantly predictive of plasma ascorbic acid whereas $H$. pylori infection became non-significant ( $\mathrm{B}=0 \cdot 10,95 \% \mathrm{CI}-0 \cdot 03,-0 \cdot 24, P=0 \cdot 1)$.

Sydney classification of gastritis was available for seventy-six H. pylori-positive patients. Mean score for acute inflammation was 1.25 (SD 0.54), for chronic inflammation was 1.80 (SD 0.69), for atrophy was 1.08 (SD $0 \cdot 63$ ), for intestinal metaplasia was 0.41 (SD 0.75) and for $H$. pylori infection density was 1.80 (SD 0.83). There were no correlations between any of these variables and either ascorbic acid or total vitamin $\mathrm{C}$ in plasma or mucosa. Chemiluminescence correlated positively with acute antral inflammation $(\rho 0.40, P<0.001)$, chronic antral inflammation $(\rho 0.28, P=0.01)$ and antral atrophy $(\rho 0.27$, $P=0 \cdot 02$ ). Surprisingly, malondialdehyde correlated negatively with acute antral inflammation $(\rho-0 \cdot 32, P=0 \cdot 006)$ but none of the other variables of gastritis.

\section{Six-week follow-up}

The results of the follow-up at 6 weeks are summarized in Table 3. Of the initial $117 \mathrm{H}$. pylori-positive patients, ninety-eight $(84 \%)$ returned and could be evaluated. Of the fifty-nine patients who received eradication therapy, fortynine returned and thirty-six were $H$. pylori-negative after 6 weeks (eradication rate $73.5 \%$ ). Four patients were indeterminate for $H$. pylori at 6 weeks and were excluded from analysis (all were $H$. pylori-positive on histology but negative on urease test and culture). H. pylori was eradicated in one patient in the placebo-vitamins group. There was no evidence that this patient had taken any antibiotics but high-dose vitamin $\mathrm{C}$ has been shown to result in eradication of $H$. pylori (Jarosz et al. 1998). This patient was also excluded from analysis. For all of the ensuing data, no significant changes were seen in the placebo-placebo group.

\section{Plasma ascorbic acid and vitamin $C$}

Plasma ascorbic acid and total vitamin C approximately doubled in both groups of patients that received vitamin supplements (Table 4). There were no changes in plasma ascorbic acid or total vitamin $\mathrm{C}$ in either group not receiving vitamin supplements and $H$. pylori eradication had no effect on plasma vitamin levels. There was, however, a significant increase in the percentage plasma vitamin $\mathrm{C}$ as ascorbic acid in the triple-vitamins group ( 86.6 to $93.3 \%, P=0.03$ ), whereas no such change was seen in the placebo-vitamins group.

\section{Tissue vitamin $C$ and ascorbic acid}

There was a significant increase in total antral vitamin $\mathrm{C}$ and smaller (non-significant) increases in antral ascorbic acid, corpus ascorbic acid and total corpus vitamin $\mathrm{C}$ in the triple-vitamins group (Table 4). In the placebo-vitamins group there were significant increases in corpus ascorbic acid and total corpus vitamin $\mathrm{C}$ along with smaller (nonsignificant) increases in antral ascorbic acid and total antral vitamin $\mathrm{C}$. When all patients receiving vitamins are 
Table 3. Follow-up of randomized patients*

\begin{tabular}{|c|c|c|c|c|c|}
\hline & Triple $†+$ vitamins $\ddagger$ & Placebo+vitamins $\ddagger$ & Triple†+placebo & Placebo+placebo & Total \\
\hline Randomized $(n)$ & 29 & 29 & 30 & 29 & 117 \\
\hline Returned at 6 weeks $(n)$ & 24 & 26 & 25 & 23 & 98 \\
\hline H. pylori negative at 6 weeks $(n)$ & 19 & 1 & 17 & 0 & 37 \\
\hline Indeterminate for $H$. pylori at 6 weeks $(n) \S$ & 1 & 1 & 2 & 0 & 4 \\
\hline
\end{tabular}

${ }^{*}$ For details of subjects and procedures, see Table 1 and p. 4.

†Triple: $H$. pylori eradication therapy comprising colloidal bismuth subcitrate, tetracycline and metronidazole for 2 weeks. $\ddagger$ Vitamins: ascorbic acid and $\alpha$-tocopherol for 4 weeks.

$\S$ All were $H$. pylori positive on histology but negative on urease test and culture and were excluded from analysis.

combined, regardless of eradication therapy, there were significant increases after treatment in antral ascorbic acid (586.5 to $695.6 \mu \mathrm{mol} / \mathrm{kg}, P=0.03)$, total antral vitamin $\mathrm{C}$ (654.7 to $824.4 \mu \mathrm{mol} / \mathrm{kg}, P=0.01$ ), corpus ascorbic acid (315.7 to $529.2 \mu \mathrm{mol} / \mathrm{kg}, \quad P=0 \cdot 001)$, and total corpus vitamin C (405.4 to $617 \cdot 2 \mu \mathrm{mol} / \mathrm{kg}, P=0 \cdot 003)$.

\section{Chemiluminescence and malondialdehyde}

Chemiluminescence fell in $18 / 19$ patients in the triplevitamins group and in $15 / 17$ in the triple-placebo group (Table 4). The difference between pre- and post-treatment chemiluminescence was significant for both groups $(P<0 \cdot 001)$. In the placebo-vitamins group, chemiluminescence fell in ten but increased in thirteen patients. Although there was a small reduction in median chemiluminescence after treatment (from 23993 to $9699 \mathrm{cpm} / \mathrm{mg}$ ) this reduction was much smaller in magnitude than that seen for the $H$. pylori eradication groups and was not significant $(P=0 \cdot 6)$. In the placebo-placebo group chemiluminescence fell in eleven and increased in ten patients $(P=1 \cdot 0)$.

Malondialdehyde fell in $13 / 18$ patients in the tripleplacebo group. The difference was significant $(P=0.03)$. In the triple-vitamins group malondialdehyde levels fell in $13 / 16$ but the difference between pre- and post-treatment values was not significant $(P=0 \cdot 1)$. In the placebo-vitamins group, malondialdehyde fell in fifteen but increased in eight $(P=0 \cdot 4)$ and in the placebo-placebo group it fell in ten and increased in twelve patients $(P=0 \cdot 7)$. Thus, vitamin supplements alone did not significantly reduce either chemiluminescence or malondialdehyde, and had no additional effect to $H$. pylori eradication.

\section{Discussion}

There has been considerable interest in the potential for antioxidant vitamins to reduce gastric cancer risk in $H$. pylori infection by attenuating oxidative stress and oxidative DNA damage. However, the precise role of ascorbic acid and other antioxidants in vivo remains uncertain. Thus, vitamin $\mathrm{C}$ supplements have been shown to reduce gastric mucosal adduct levels in one study (Dyke et al. 1994) whereas in another, patients given supplements of $\alpha$-tocopherol and $\beta$-carotene were more likely to develop bronchial carcinoma than unsupplemented patients (The Alpha-Tocopherol, Beta-Carotene Cancer Prevention Study Group, 1994; Omenn et al. 1996). Furthermore, vitamin C and $\mathrm{E}$ supplements have been shown to reduce oxidative stress in peripheral lymphocytes and abrogate Fe-induced oxidative stress in the rat intestine (Brennan et al. 2000; Srigiridhar \& Nair, 2000). There is a need, therefore, to clarify the antioxidant effects of vitamin supplements in the gastric mucosa before advocating this approach.

This is the first study to have randomized $H$. pylori-infected patients to vitamin $\mathrm{C}$ and $\mathrm{E}$ supplements and eradication therapy, alone and in combination, and examine the effect of these treatments on ROS activity in gastric biopsies. There was no specific determination of compliance but plasma ascorbic acid more than doubled in the vitamin-supplemented patients to concentrations that are considered to be the plateau for ascorbic acid. This is good evidence that the tablets were taken largely as prescribed, and that the dose of ascorbic acid, at seven times the recommended daily intake, was sufficient for the purposes of the study (Levine et al. 1996).

Our baseline data closely reflect previous studies, some from our own department (Sobala et al. 1989; Banerjee et al. 1994; Davies et al. 1994; Farinati et al. 1996; Drake et al. 1998). ROS and malondialdehyde levels were elevated in $H$. pylori infection and malondialdehyde concentrations correlated significantly with chemiluminescence. Ascorbic acid and total vitamin $\mathrm{C}$ were highly concentrated in the mucosa, and levels were not affected by $H$. pylori infection. Plasma ascorbic acid, total vitamin $\mathrm{C}$, and the percentage plasma vitamin $\mathrm{C}$ as ascorbic acid were all significantly diminished in $H$. pylori-positive patients compared with controls. This latter finding is in contrast with previous work and probably reflects the larger number of patients in our present study (Phull et al. 1998). It is unlikely, however, that the reduction in plasma ascorbic acid is a direct effect of $H$. pylori infection since levels did not alter after eradication of the organism. A lack of independent effect was confirmed by multiple linear regression. It is more likely that the difference reflects different dietary intake or other factors such as socio-economic status. This is reflected by the lower proportion of smokers in the control group, and is consistent with studies of nutritional factors and $H$. pylori infection rates in Colombian children (Goodman et al. 1997).

Eradication of $H$. pylori resulted in expected reductions in mucosal chemiluminescence and malondialdehyde concentrations, in line with previous studies (Farinati et al. 1996; Waring et al. 1996; Drake et al. 1998). Vitamin supplements, either alone or in concert with $H$. pylori eradication, led to increases in tissue and plasma ascorbic acid and total vitamin $\mathrm{C}$ concentrations. However, supplements had a negligible effect on tissue chemiluminescence and malondialdehyde. It is possible that a small effect of vitamin supplements on ROS 
Table 4. Paired plasma, antral and corpus ascorbic acid and total vitamin C, chemiluminescence and malondialdehyde for patients with Helicobacter pylori gastritis, before and 6 weeks after treatment*

(Median values and interquartile ranges)

\begin{tabular}{|c|c|c|c|c|c|c|c|c|c|c|c|c|c|c|c|c|}
\hline \multirow[b]{3}{*}{ Time (weeks) } & \multicolumn{4}{|c|}{ Triple†+vitamins $¥(n 19) \S$} & \multicolumn{4}{|c|}{ Placebo+vitaminsł (n 24)\| } & \multicolumn{4}{|c|}{ Triple†+placebo $(n 17) \S$} & \multicolumn{4}{|c|}{ Placebo+placebo (n 23) \| } \\
\hline & & 0 & & 6 & & 0 & & 6 & & 0 & & 6 & & 0 & & 6 \\
\hline & Median & $\begin{array}{l}\text { Interquartile } \\
\text { range }\end{array}$ & Median & $\begin{array}{l}\text { Interquartile } \\
\text { range }\end{array}$ & Median & $\begin{array}{l}\text { Interquartile } \\
\text { range }\end{array}$ & Median & $\begin{array}{l}\text { Interquartile } \\
\text { range }\end{array}$ & Median & $\begin{array}{l}\text { Interquartile } \\
\text { range }\end{array}$ & Median & $\begin{array}{l}\text { Interquartile } \\
\text { range }\end{array}$ & Median & $\begin{array}{l}\text { Interquartile } \\
\text { range }\end{array}$ & Median & $\begin{array}{l}\text { Interquartile } \\
\text { range }\end{array}$ \\
\hline $\begin{array}{l}\text { Plasma ascorbic } \\
\text { acid ( } \mu \mathrm{mol} / \mathrm{l})\end{array}$ & 29.8 & $10 \cdot 8-44 \cdot 3$ & $65.9 \S \S$ & $53 \cdot 4-90 \cdot 8$ & $36 \cdot 3$ & $11 \cdot 4-61.9$ & $74 \cdot 9^{\star \star \star}$ & $58 \cdot 5-81 \cdot 8$ & $23 \cdot 6$ & $7 \cdot 1-58 \cdot 2$ & $24 \cdot 4$ & $9 \cdot 1-63 \cdot 6$ & $35 \cdot 2$ & $14 \cdot 2-65 \cdot 3$ & $31 \cdot 2$ & $16 \cdot 5-53 \cdot 9$ \\
\hline $\begin{array}{l}\text { Plasma total } \\
\text { vitamin } C(\mu \mathrm{mol} / \mathrm{l})\end{array}$ & $39 \cdot 7$ & $13 \cdot 6-48 \cdot 3$ & 73.2ł & $56 \cdot 2-94 \cdot 8$ & $40 \cdot 3$ & $14 \cdot 2-68 \cdot 1$ & $78 \cdot 9^{\star \star \star}$ & $69 \cdot 8-85 \cdot 7$ & 33.2 & $8 \cdot 2-63 \cdot 0$ & 34.6 & $10 \cdot 2-68 \cdot 1$ & 39.7 & $18 \cdot 7-62 \cdot 5$ & 37.5 & $20 \cdot 4-60 \cdot 8$ \\
\hline $\begin{array}{l}\text { Antral ascorbic acid } \\
(\mu \mathrm{mol} / \mathrm{kg})\end{array}$ & 546.2 & $266 \cdot 3-739 \cdot 8$ & 691.6 & $418.5-973.2$ & 647.9 & $343 \cdot 5-855 \cdot 7$ & 699.5 & $496 \cdot 3-1071 \cdot 4$ & 543.4 & $328 \cdot 1-974 \cdot 9$ & 424.1 & $271 \cdot 4-715 \cdot 4$ & 634.2 & $341 \cdot 2-855 \cdot 7$ & 692.7 & $360 \cdot 6-946.0$ \\
\hline $\begin{array}{l}\text { Antral total Vitamin } \\
\qquad \mathrm{C}(\mu \mathrm{mol} / \mathrm{kg})\end{array}$ & 568.9 & $371 \cdot 9-853 \cdot 4$ & $760 \cdot 9+\dagger$ & $530 \cdot 3-1151 \cdot 5$ & $719 \cdot 4$ & $445 \cdot 7-995 \cdot 4$ & 854.0 & $607 \cdot 5-1188 \cdot 4$ & 536.0 & $382 \cdot 7-1101 \cdot 0$ & 498.0 & $356 \cdot 0-804 \cdot 6$ & 668.9 & $427 \cdot 0-965 \cdot 8$ & $859 \cdot 1$ & $644 \cdot 5-1060 \cdot 1$ \\
\hline $\begin{array}{r}\text { Corpus ascorbic } \\
\text { acid ( } \mu \mathrm{mol} / \mathrm{kg} \text { ) }\end{array}$ & $405 \cdot 4$ & $168 \cdot 6-534 \cdot 3$ & 473.5 & $316 \cdot 3-670 \cdot 0$ & $304 \cdot 3$ & $189 \cdot 1-472 \cdot 4$ & $541 \cdot 1^{\star \star}$ & $241 \cdot 9-794 \cdot 4$ & $392 \cdot 9$ & $80 \cdot 1-493 \cdot 4$ & 231.7 & $84 \cdot 6-449 \cdot 1$ & 458.8 & $254 \cdot 9-679 \cdot 1$ & 383.8 & $170 \cdot 3-546 \cdot 2$ \\
\hline $\begin{array}{l}\text { Corpus total vitamin } \\
\qquad(\mu \mathrm{mol} / \mathrm{kg})\end{array}$ & $480 \cdot 4$ & $290 \cdot 7-725 \cdot 1$ & $562 \cdot 7$ & $440 \cdot 6-813 \cdot 7$ & $403 \cdot 1$ & $270 \cdot 8-652 \cdot 4$ & $663 \cdot 2+t \dagger$ & $353 \cdot 2-988 \cdot 5$ & $433 \cdot 2$ & $178 \cdot 9-608 \cdot 1$ & $370 \cdot 2$ & $135 \cdot 1-533 \cdot 7$ & 548.5 & $295 \cdot 8-804 \cdot 0$ & $516 \cdot 1$ & $367 \cdot 4-689 \cdot 9$ \\
\hline $\begin{array}{l}\text { Chemiluminescence } \\
\text { (c.p.m./mg) }\end{array}$ & 17316 & $11270-106386$ & $684^{* \star \star}$ & $374-1264$ & 23993 & $6698-54525$ & 9699 & $1899-31820$ & 9593 & $2504-36966$ & $919^{* \star *}$ & $278-1449$ & 14591 & $5849-35237$ & 13151 & $4301-41690$ \\
\hline $\begin{array}{l}\text { Malondialdehyde } \\
(\mu \mathrm{mol} / \mathrm{kg})\end{array}$ & $97 \cdot 7$ & $77 \cdot 3-140 \cdot 5$ & 89.8 & $68 \cdot 7-131 \cdot 1$ & $124 \cdot 5$ & $97 \cdot 9-141 \cdot 9$ & $115 \cdot 7$ & $98 \cdot 6-113 \cdot 1$ & $126 \cdot 3$ & $98 \cdot 1-146 \cdot 6$ & $92.8 \S \S$ & $70 \cdot 1-113 \cdot 9$ & $121 \cdot 9$ & $85 \cdot 1-137 \cdot 1$ & $112 \cdot 3$ & $87 \cdot 8-135 \cdot 7$ \\
\hline
\end{tabular}

${ }^{*}$ For details of subjects and procedures, see Table 1 and p. 4.

†Triple: H. pylori eradication therapy comprising colloidal bismuth subcitrate, tetracycline and metronidazole for 2 weeks.

$\ddagger$ Vitamins: ascorbic acid and $\alpha$-tocopherol for 4 weeks.

$\S$ For patients receiving triple therapy, data are for those in whom $H$. pylori was succesfully eradicated.

$\|$ For patients receiving placebo triple therapy, data are for those who remained H. pylori positive.

Median values were significantly different from paired pre-treatment values (wilcoxon signed ranks test): $\dagger \dagger P=0.04, \ddagger \ddagger P=0.03, \S \S P=0.02,{ }^{* *} P=0.01, t \dagger \dagger P=0.004$, ${ }^{* \star *} P<0.001$. All other paired comparisons were nonsignificant. 
activity has been missed due to the relatively small numbers in each group and the large $\mathrm{CV}$ for chemiluminescence. It is clear from the results, however, that any effect of vitamins is far less than eradication of $H$. pylori. The reduction in chemiluminescence after treatment of the infection was several orders of magnitude greater than that of vitamin supplements and it would be difficult to demonstrate an effect over and above this. Likewise, the results relating to malondialdehyde indicate that the most effective treatment is $H$. pylori eradication and vitamin supplements do not add to this effect.

The failure of antioxidant vitamin supplements to significantly effect levels of ROS is not surprising, because, even in the inflamed stomach, ascorbic acid is highly concentrated into the mucosa. Concentrations of the ascorbyl radical are increased in the mucosa of $H$. pylori gastritis, but its concentration remains considerably lower than ascorbic acid (Drake et al. 1996). This lends support to an antioxidant role for ascorbic acid but suggests that, even in the presence of continued inflammation, the scavenging capability of ascorbic acid is replete. Supplements are only likely to be of use when ascorbic acid stores are significantly diminished.

A second consideration is that ascorbic acid can act not only as antioxidant but also, in the presence of transition metals, as pro-oxidant (Halliwell \& Gutteridge, 1998). In keeping with this, and consistent with earlier work, we found that antral mucosal ascorbic acid had a weak positive correlation with chemiluminescence (Drake et al. 1998; Everett et al. 2001). Alternative explanations for this relationship include an influx of ascorbic acid into the mucosa in response to oxidative stress or as a consequence of the rich content of ascorbic acid found in leucocytes. However, the possibility of ascorbic acid acting as pro-oxidant in vivo suggests that, depending on the circumstances, vitamin supplements might have either a beneficial or a detrimental effect (Herbert, 1994).

It is worthy of comment that epidemiological data mainly support a protective effect of high fruit and vegetable intake rather than antioxidants per se. Our results do not conflict with this observation, which may result from the presence of other compounds such as folic acid or the balance between different micronutrients in fruits and vegetables (La Vecchia et al. 1994). Furthermore, the results of the present study do not rule out the possibility that antioxidant vitamin supplements may prevent the development of gastritis. Indeed it has already been observed that diets high in vitamin $\mathrm{C}$ may prevent infection with H. pylori (Goodman et al. 1997; Jarosz et al. 1998). Vitamin supplements could also have a beneficial effect on the formation of $N$-nitroso compounds in gastric juice. However, although it is tempting to speculate that longer and larger doses of antioxidants may yet be shown to be beneficial, the potential for harm is also present. Not only is ascorbic acid potentially pro-oxidant but recent in vitro work has also shown that vitamin $\mathrm{C}$ may mediate formation of genotoxins from lipid hydroperoxides in the absence of transition metal ions (Lee et al. 2001). These issues may only be settled by large population studies or using direct measurements of DNA damage.
In conclusion, we have found that dietary supplementation of antioxidant vitamin supplements do not reduce ROS activity in the gastric mucosa. Oxidative stress, and hence oxidative DNA damage, in the gastric mucosa are only likely to be reduced if $H$. pylori is eradicated, regardless of dietary manipulation.

\section{Acknowledgements}

This study was supported by a grant from the Ivy Hobson Trust for Cancer Research.

\section{References}

Banerjee S, Hawksby C, Miller S, Dahill S, Beattie A \& McColl K (1994) Effect of Helicobacter pylori and its eradication on gastric juice ascorbic acid. Gut 35, 317-322.

Block G (1991) Vitamin C and cancer prevention: the epidemiologic evidence. American Journal of Clinical Nutrition 53, 270S-282S.

Brennan LA, Morris GM, Wasson GR, Hannigan BM \& Barnett YA (2000) The effect of vitamin C or vitamin E supplementation on basal and $\mathrm{H}_{2} \mathrm{O}_{2}$ induced DNA damage in human lymphocytes. British Journal of Nutrition 84, 195-202.

Cadenas S, Lertsiri S, Otsuka M, Barja G \& Miyazawa T (1996) Phospholipid hydroperoxides and lipid peroxidation in liver and plasma ODS rats supplemented with alpha-tocopherol and ascorbic acid. Free Radical Research 24, 485-493.

Correa P (1995) The role of antioxidants in gastric carcinogenesis. Critical Reviews in Food Science and Nutrition 35, 59-64.

Davies GR, Simmonds NJ, Stevens TRJ, Sheaff MT, Banatvala N, Laurenson IF, Blake DR \& Rampton DS (1994) Helicobacter pylori stimulates antral mucosal reactive oxygen metabolite production in vivo. Gut 35, 179-185.

Dixon MF, Genta RM \& Yardley JH (1996) Correa P and the participants of the International Workshop on the Histopathology of Gastritis Classification and grading of gastritis. The updated Sydney system. American Journal of Surgical Pathology 20, 1161-1181.

Drake I, Davies M, Mapstone N, Dixon M, Schorah C, White K, Chalmers D \& Axon A (1996) Ascorbic acid may protect against human gastric cancer by scavenging mucosal oxygen radicals. Carcinogenesis 17, 559-562.

Drake I, Mapstone N, Schorah C, White K, Chalmers D, Dixon M \& Axon A (1998) Reactive oxygen species activity and lipid peroxidation in Helicobacter pylori associated gastritis: relation to gastric mucosal ascorbic acid concentrations and effect of $H$. pylori eradication. Gut 42, 768-771.

Dyke G, Craven J, Hall R \& Garner R (1994) Effect of vitamin C supplementation on gastric mucosal DNA damage. Carcinogenesis 15, 291-295.

Emma AM \& Fitzgerald GA (2000) Indices of lipid peroxidation in vivo: strengths and limitations. Free Radical Biology and Medicine 28, 1745-1750.

Everett SM, Singh R, Leuratti C, White KLM, Neville P, Greenwood D, Marnett LJ, Schorah CJ, Forman D, Shuker D \& Axon ATR (2001) Levels of malondialdehyde-deoxyguanosine in the gastric mucosa - relationship with lipid peroxidation, ascorbic acid and Helicobacter pylori. Cancer Epidemiology and Biomarkers 10, 369-376.

Farinati F, Della Libera G, Cardin R, Molari A, Plebani M, Rugge M, Di Mario F \& Naccarato R (1996) Gastric antioxidant, nitrites, and mucosal lipoperoxidation in chronic gastritis and Helicobacter pylori infection. Journal of Clinical Gastroenterology 22, 275-281. 
Frei B (1991) Ascorbic acid protects lipids in human plasma and low density lipoprotein against oxidative damage. American Journal of Clinical Nutrition 54, 1113S-1118S.

Goodman K, Correa P, Tengana Aux H, DeLany J \& Collazos T (1997) Nutritional factors and Helicobacter pylori infection in Colombian children. Journal of Pediatric Gastroenterology and Nutrition 25, 507-515.

Guyton KZ \& Kensler TW (1993) Oxidative mechanisms in carcinogenesis. British Medical Bulletin 49, 523-544.

Halliwell B \& Gutteridge J (1998) Free Radicals in Biology and Medicine, Oxford: Oxford University Press.

Herbert V (1994) The antioxidant supplement myth. American Journal of Clinical Nutrition 60, 157-158.

International Agency for Research on Cancer (1994) IARC Monographs on the Evaluation of Carcinogenic Risks to Humans. Shistosomes, Liver Flukes and Helicobacter pylori. Monograph 61, Lyon: IARC Scientific Publications.

Jackson JH, Gajewski E, Schraufstatter IU, Hyslop PA, Fuciarelli AF, Cochrane CG \& Dizdaroglu M (1989) Damage to the bases in DNA induced by stimulated human neutrophils. Journal of Clinical Investigation 84, 1644-1649.

Jarosz M, Dzieniszewski J, Dabrowska-Ufniarz E, Wartanowicz M, Ziemlariski S \& Reed PI (1998) Effects of high vitamin C doses on Helicobacter pylori infection and total vitamin $\mathrm{C}$ concentration in gastric juice. European Journal of Cancer Prevention 7, 449-454.

Knekt P, Aromaa A, Maatela J, Aaran R, Nikkari T, Hakama M, Hakulinen T, Peto R \& Teppo L (1991) Vitamin E and cancer prevention. American Journal of Clinical Nutrition 53, 283S$286 \mathrm{~S}$.

La Vecchia C, Ferraroni M, D’Avanzo B, Decarli A \& Franceschi $S$ (1994) Selected micronutrient intake and the risk of gastric cancer. Cancer, Epidemiology, Biomarkers and Prevention 3, 393-398.

Lee SH, Oe T \& Blair IA (2001) Vitamin C-induced decomposition of lipid hydroperoxides to endogenous genotoxins. Science 292, 2083-2086.

Levine M, Conry-Cantilena C, Wang Y, Welch R, Washko P, Dhariwal K, Park J, Laxarev A, Graumilch J, King J \& Cantilena L (1996) Vitamin C pharmacokinetics in healthy volunteers: Evidence for a recommended dietary allowance. Proceedings of the National Academy of Science, USA 93, 3704-3709.

Marnett LJ (1994) DNA adducts of $\alpha, \beta$-unsaturated aldehydes and dicarbonyl compounds. In DNA Adducts: Identification and Biological Significance, Vol 125, pp. 151-163 [K Hemminki, A Dipple, DEG Shuker, FF Kadlubar, D Segerback and H Bartsch, editors]. Lyon: IARC Scientific Publications.
Mirvish S, Wallcave L, Eagen M \& Shubik P (1972) AscorbateNitrite reaction: Possible means of blocking the formation of carcinogenic N-nitroso compounds. Science 177, 65-67.

Omenn G, Goodman G, Thornquist M, Balmes J, Cullen MR, Glass A, Keogh JP, Meyskens FL Jr, Valanis B, Williams JH Jr, Barnhart S, Cherniack MG, Brodkin CA \& Hammar S (1996) Risk factors for lung cancer and for intervention effects in CARET, the Beta-Carotene and Retinal Efficacy Trial. Journal of the National Cancer Institute 88, 1550-1559.

Parkin DM, Pisani P \& Ferlay J (1993) Estimates of worldwide incidence of eighteen major cancers in 1985. International Journal of Cancer 54, 594-606.

Phull P, Price A, Thorniley M, Green C \& Jacyna M (1998) Plasma free radical activity and antioxidant vitamin levels in dyspeptic patients: correlation with smoking and Helicobacter pylori infection. European Journal of Gastroenterology and Hepatology 10, 573-577.

Simmonds N, Allen R, Stevens T, Van Someren N, Blake D \& Rampton D (1992) Chemiluminescence assay of mucosal reactive oxygen metabolites in inflammatory bowel disease. Gastroenterology 103, 186-196.

Sobala G, Schorah C, Sanderson M, Dixon M, Tompkins D, Godwin P \& Axon A (1989) Ascorbic acid in the human stomach. Gastroenterology 97, 357-363.

Sobala GM, Pignatelli B, Schorah CJ, Bartsch H, Sanderson M, Dixon MF, Shire S, King RFG \& Axon ATR (1991) Levels of nitrite, nitrate, $\mathrm{N}$-nitroso compounds, ascorbic acid and total bile acids in gastric juice of patients with and without precancerous conditions of the stomach. Carcinogenesis 12, 193-198.

Srigiridhar K \& Nair KM (2000) Supplementation with $\alpha$ tocopherol or a combination of $\alpha$-tocopherol and ascorbic acid protects the gastrointestinal tract of iron-deficient rats against iron-induced oxidative damage during iron repletion. British Journal of Nutrition 84, 165-173.

The Alpha-Tocopherol, Beta-Carotene Cancer Prevention Study Group (1994) The effects of vitamin E and beta carotene on the incidence of lung cancer and other cancers in male smokers. New England Journal of Medicine 12, 289-303.

Waring A, Drake I, Schorah C, White K, Lynch D, Axon A \& Dixon M (1996) Ascorbic acid and total vitamin C concentrations in plasma, gastric juice, and gastrointestinal mucosa: effects of gastritis and oral supplementation. Gut 38, $171-176$.

Yagi K (1976) A simple fluorimetric assay for lipoperoxide in blood plasma. Biochemical Medicine 15, 212-216. 